\title{
EPIDEMIOLOGICAL, CLINICAL AND LABORATORY ANALYSIS OF PATIENTS WITH TAKAYASU ARTERITIS AT HOSPITAL UNIVERSITÁRIO CASSIANO ANTÔNIO DE MORAES (HUCAM/UFES)
}

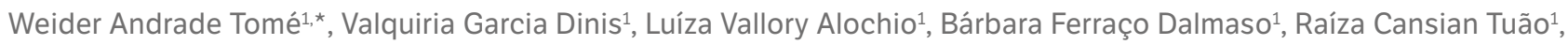
Letícia Fonseca Favarato ${ }^{1}$, Ketty Lysie Libardi Lira Machado ${ }^{1}$, Ruben Horst Duque ${ }^{1}$, Valéria Valim ${ }^{1}$, Samira Tatiyama Miyamoto ${ }^{1}$

1.Universidade Federal do Espírito Santo, Vitória (ES), Brazil.

${ }^{\star}$ Corresponding author: weidertome@hotmail.com

\section{BACKGROUND}

Takayasu's arteritis (TA) is an autoimmune disease characterized by large vessel vasculitis. Takayasu's arteritis has a higher prevalence in Asia, predominantly affecting young women between the second and third decade of life. There are few records on the profile of patients with TA in Brazil. The objective of this study is to characterize a cohort of patients from a tertiary hospital.

\section{METHODS}

The study population consisted of patients over 18 years of age diagnosed with TA according to the criteria of the American College of Rheumatology (ACR) 1990 and undergoing outpatient medical follow-up at the vasculitis outpatient clinic of University Hospital of Federal University of Espírito Santo (HUCAM-UFES/EBSERH).

\section{RESULTS}

Our study evaluated 15 patients diagnosed with TA, aged $41.5( \pm 15)$ years old, disease duration of 13.9 years and a mean age at diagnosis of 27.6 years. We observed a predominance of females (86.58\%) and African descendants (80\%). Regarding arterial involvement, the most frequently affected sites were: left internal carotid artery (80\%); abdominal segment of the descending aorta (73.3\%) and right renal artery (60\%). It was observed that $73.3 \%$ had hypertension, $53.3 \%$ dyslipidemia, $20 \%$ chronic kidney disease, $13.3 \%$ hypothyroidism and $13.3 \%$ osteopenia/osteoporosis; in addition, $6.6 \%$ were smokers. No patient had diabetes or was alcoholic. It was also identified that 5 (33.3\%) patients had a diagnosis of latent tuberculosis. Regarding vascular complications, no patient had acute myocardial infarction or ischemic stroke. When compared by race, there was no statistical difference in terms of comorbidities or vascular complications between groups. The comparative analysis between the sexes revealed that women had more extensive disease with involvement of the cervical and thoracic vessels and extremities of the upper and lower limbs; while men presented involvement only of the abdominal aorta and its visceral branches. Regarding comorbidities, women also had more comorbidities, such as osteopenia/osteoporosis, hypothyroidism and chronic kidney disease. Most patients required the use of some immunosuppressant, with methotrexate being the most used. We observed that $66.6 \%$ of patients were refractory to the use of conventional immunosuppressants and required the use of immunobiologicals, with infliximab being the most prescribed drug.

\section{CONCLUSION}

The studied population showed late diagnosis and severe disease with female and Afro-descendant predominance, high prevalence of hypertension, dyslipidemia, chronic kidney dysfunction and latent tuberculosis, mostly were refractory to immunosuppressant and required immunobiological therapy. Women had more extensive disease of type $\mathrm{V}$ disease compared to type IV in male.

\section{KEYWORDS}

Vasculitis, Takayasu, HUCAM. 